\title{
Telmisartan prevents proliferation and promotes apoptosis of human ovarian cancer cells through upregulating PPAR $\gamma$ and downregulating MMP-9 expression
}

\author{
ZHICHEN PU ${ }^{1,2}$, MIN ZHU ${ }^{1}$ and FANDOU KONG ${ }^{1}$ \\ ${ }^{1}$ Department of Obstetrics and Gynecology, The First Affiliated Hospital of Dalian Medical University, \\ Dalian, Liaoning 116011; ${ }^{2}$ Department of Clinical Pharmacy, Yijishan Hospital of Wannan Medical College, \\ Anhui Center for Drug Clinical Evaluation, Wuhu, Anhui 241001, P.R. China
}

Received November 24, 2014; Accepted September 25, 2015

DOI: $10.3892 / \mathrm{mmr} .2015 .4512$

\begin{abstract}
The mortality rate of ovarian cancer is the highest of all gynecological malignancies. Telmisartan is a commonly used clinical angiotensin receptor blocker, which has antihypertensive, anti-inflammatory and antithrombotic effects. In the present study, it was investigated whether telmisartan could exert anticancer effects on ovarian cancer cells through upregulating peroxisome proliferator-activated receptor $\gamma$ (PPAR $\gamma)$ and downregulating matrix metalloproteinase-9 (MMP-9) expression. A 3.3-(4,5-dimethylthiazol-2-yl)-2,5-diphenyltetrazolium bromide assay was conducted to analyze the proliferation of HEY cells. A Caspase-3 Activity Assay kit and an Annexin V-fluorescein isothiocyanate/propidium iodide kit were used to analyze the apoptosis of HEY cells. In addition, a gelatin zymography assay and reverse trancription-quantitative polymerase chain reaction were included to analyze the expression of PPAR $\gamma$ and MMP-9 in HEY cells. The data showed that telmisartan could significantly decrease cell viability and induce the apoptosis of HEY cells in a time- and dose-dependent manner. Furthermore, telmisartan could also dose-dependently increase the expression of PPAR $\gamma$ and decrease the expression of MMP-9 in HEY cells. In addition, downregulation of the expression of PPAR $\gamma$ by small interfering (si)RNA could reduce the effect of telmisartan on ovarian cancer cells and increase the expression of MMP-9. In conclusion, the results indicated that telmisartan prevents proliferation and promotes apoptosis of human ovarian cancer cells by upregulating PPAR $\gamma$ and downregulating MMP-9 expression.
\end{abstract}

Correspondence to: Ms. Min Zhu, Department of Obstetrics and Gynecology, The First Affiliated Hospital of Dalian Medical University, 222 Zhong Shan Road, Dalian, Liaoning 116011, P.R. China

E-mail: minzhuhj@163.com

Key words: matrix metalloproteinase-9, telmisartan, ovarian cancer, peroxisome proliferator-activated receptor $\gamma$

\section{Introduction}

Ovarian cancer is one of the most common types of malignant tumor of the female reproductive organs, with the third highest incidence rate after cervical cancer and uterine cancer (1). The mortality rate of epithelial ovarian cancer is the highest of all gynecological tumors (2). Among the different types of ovarian cancer, epithelial tumors are the most common, and the second most common are malignant germ cell tumors (3). Patients with epithelial ovarian cancer with tumors that are confined to the ovaries at the time of surgery only account for $30 \%$ of all cases, with the majority experiencing spread to the uterus, bilateral accessory, and omental and pelvic organs; therefore, there is a problem with early diagnosis (4).

Peroxisome proliferator-activated receptor (PPAR) is a type of nuclear transcription factor activated by ligands, and is a member of the nuclear hormone receptor superfamily. Recent research has demonstrated that PPAR $\gamma$ is highly expressed in a number of types of cancer, including stomach, pancreatic, breast, esophageal and lung cancer (5-9). Certain studies have indicated that PPAR $\gamma$ can adjust the level of matrix metalloproteinases (MMPs) and affect trophoblast invasion, resulting in the restriction of fetal growth (10-12). Thus, agonists of PPAR $\gamma$ can effect the activity of MMP-9 (13). A previous study showed that following ligand activation in K562 and HL-60 human myeloid cell leukemia cell lines, PPAR $\gamma$ can inhibit the adhesion and invasion of cells by affecting the expression of MMP-2 and -9 (14).

Telmisartan is a common clinical antihypertensive agent which is an angiotensin receptor inhibitor (15). Studies have demonstrated that telmisartan not only protects against cerebral ischemia through adjusting blood pressure, but also by activating PPAR $\gamma$, which results in antioxidant and anti-inflammatory effects reducing the volume of cerebral infarction and protecting against cerebral ischemia (16-17). Telmisartan can inhibit MMP-9 by activating PPAR $\gamma$, which significantly reduces ventricular remodeling after myocardial infarction and retards atherosclerosis (18). Therefore, the present study was conducted to investigate the anticancer effects of telmisartan. 
In the current study, telmisartan was demonstrated to decrease proliferation and promote the apoptosis of human ovarian cancer cells by upregulating PPAR $\gamma$ and downregulating MMP-9 expression.

\section{Materials and methods}

Chemicals. Dulbecco's modified Eagle's Medium (DMEM) and fetal bovine serum (FBS) were purchased from Gibco-BRL (Rockville, MD, USA). 3.3-(4,5-dimethylthiazol-2-yl)-2, 5-diphenyltetrazolium bromide (MTT) was purchased from Promega Corporation (Madison, WI, USA). The Caspase-3 Activity Assay kit was purchased from Beyotime Institute of Biotechnology (Nanjing, China). The Annexin V-fluorescein isothiocyanate (FITC)/propidium iodide (PI) kit was purchased from BD Pharmingen (San Diego, CA, USA). RNeasy Plus Mini kit was purchased from Nanjing KeyGen Biotech Co., Ltd. (Nanjing, China). Transcriptor First Strand cDNA Synthesis kit was purchased from Sangon Biotech (Shanghai, China).

Cell culture. HEY human ovarian cancer cells were obtained from the Animal Lab of the First Affiliated Hospital of Dalian Medical University (Dalian, China). HEY cells were maintained in DMEM, containing 10\% FBS, $100 \mathrm{U} / \mathrm{ml}$ penicillin and $100 \mathrm{mg} / \mathrm{ml}$ streptomycin (Amresco LLC, Solon, $\mathrm{OH}$, USA) at $37^{\circ} \mathrm{C}$ in $5 \% \mathrm{CO}_{2}$

MTT assay. HEY cells $\left(1 \times 10^{4}\right)$ were seeded in 96-well plates and treated with telmisartan (Sigma-Aldrich, St. Louis, MO, USA) (Fig. 1) at different concentrations (0, 1, 10 and $100 \mu \mathrm{M})$ for $0,24,48$ and $72 \mathrm{~h}$ (19). The proliferation of HEY cells was determined by an MTT assay. MTT (20 $\mu \mathrm{l}, 5 \mathrm{mg} / \mathrm{ml})$ was added to each well and incubated for $4 \mathrm{~h}$. Then, the medium in each well was removed. Approximately $150 \mu$ l dimethylsulfoxide (Amresco LLC) was added to each well and incubated for $10 \mathrm{~min}$ at room temperature whilst being agitated. The plates were read with a microplate reader (Model 680; Bio-Rad Laboratories, Inc., Hercules, CA, USA) at $570 \mathrm{~nm}$.

Caspase-3 activity measurement. HEY cells $\left(2.0 \times 10^{5} / \mathrm{ml}\right)$ were plated in 6-well plates and incubated for $24 \mathrm{~h}$. After treatment with telmisartan $(0,1,10$ or $100 \mu \mathrm{M})$, the activity of caspase- 3 was detected using the caspase-3 colorimetric assay kit (Beyotime Institute of Biotechnology), according to the manufacturer's instructions. Samples were measured with an ELISA reader (Model 680; Bio-Rad Laboratories, Inc.) at a wavelength of $405 \mathrm{~nm}$.

Flow cytometric analysis for detecting cellular apoptosis. In accordance with the manufacturer's instructions, apoptosis was detected using an Annexin V-FITC/PI kit. Briefly, HEY cells were stained with $5 \mu \mathrm{l}$ Annexin V-FITC and $5 \mu \mathrm{l}$ PI for $15 \mathrm{~min}$ at room temperature in the dark. Cell apoptosis was determined using a flow cytometer (Gallios; Beckman Coulter, Inc., Brea, CA, USA).

Reverse transcription-quantitative polymerase chain reaction (RT-qPCR) analysis of PPAR $\gamma$ expression. In accordance with the manufacturer's instructions of the RNeasy Plus Mini kit,

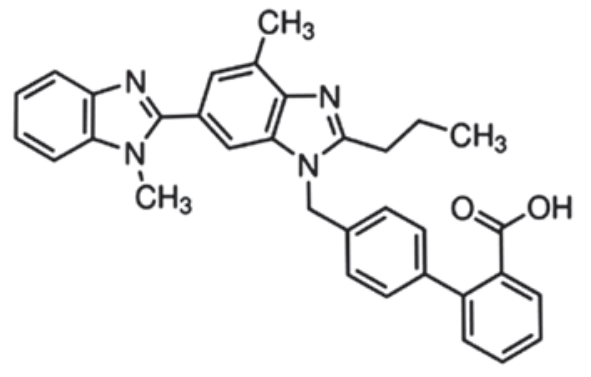

Figure 1. Chemical structure of telmisartan.

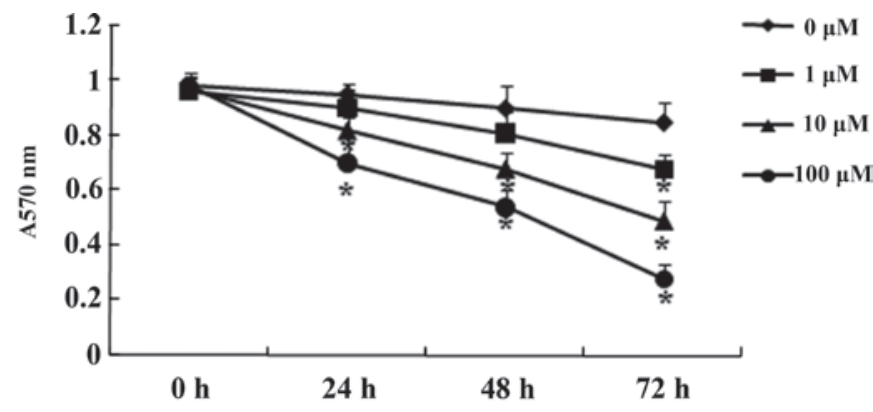

Figure 2. 3.3-(4,5-dimethylthiazol-2-yl)-2, 5-diphenyltetrazolium bromide analysis of cell proliferation following treatment with different concentrations of telmisartan $(0,1,10$ and $100 \mu \mathrm{M})$. ${ }^{*} \mathrm{P}<0.01$ compared with the $0 \mu \mathrm{M}$ telmisartan treatment group.

total RNA $(1 \mu \mathrm{g})$ was isolated from HEY cells. cDNA was produced by reverse transcription using the Transcriptor First Strand cDNA Synthesis kit. The synthesized cDNA was used as a template to estimate the quantity of gene transcription by qPCR. The amplification conditions were as follows: $94^{\circ} \mathrm{C}$ for $10 \mathrm{sec}, 58^{\circ} \mathrm{C}$ for $30 \mathrm{sec}$, and $72^{\circ} \mathrm{C}$ for $10 \mathrm{sec}$ for 35 cycles. The following primer sequences were used: PPAR $\gamma$, forward, 5'-GCGGAAGCCCTTTGGTGA-3' and reverse 5'-TGCAGC AGGTTGTCTTGGATG-3'; GAPDH, forward, 5'-CCCCCA ATGTATCCGTTGTG-3' and reverse 5'-TGCAGCAGGTTG TCTTGGATG-3'. The Ct was obtained using the Sequence Detection System software (Applied Biosystems; Thermo Fisher Scientific, Waltham, MA, USA).

Analysis of MMP-9 expression. A gelatin zymography assay was performed to analyze the expression of MMP-9. Briefly, the medium of each well was collected, combined with an equal volume of sodium dodecyl sulfate (SDS) sample buffer and resolved in $10 \%$ polyacrylamide gels containing $0.1 \%$ gelatin (Beyotime Institute of Biotechnology). After electrophoresis, the gel was washed with 2.5\% Triton X-100 (Beyotime Institute of Biotechnology) for $0.5-1 \mathrm{~h}$, and incubated in a reaction buffer at $37^{\circ} \mathrm{C}$ for $12 \mathrm{~h}$. Following incubation, the gel was stained with $0.05 \%$ Coomassie brilliant blue R-250 (Bio-Rad Laboratories, Inc.). A gelatin zymography assay was performed to analyze the expression of MMP-9 as previously described (20).

Silencing of PPAR $\gamma$. PPAR $\gamma$ small interfering (si)RNA was obtained from Sangon Biotech. The following primers were used: S1 forward primer: 5'-AGAUAAAGCUUCUGGAUU UdTdT-3' and reverse primer: 5'-dTdTUCUAUUUCGAAGAC CUAAA-3'; S2 forward primer: 5'-AGGAAAGACAACAGA 

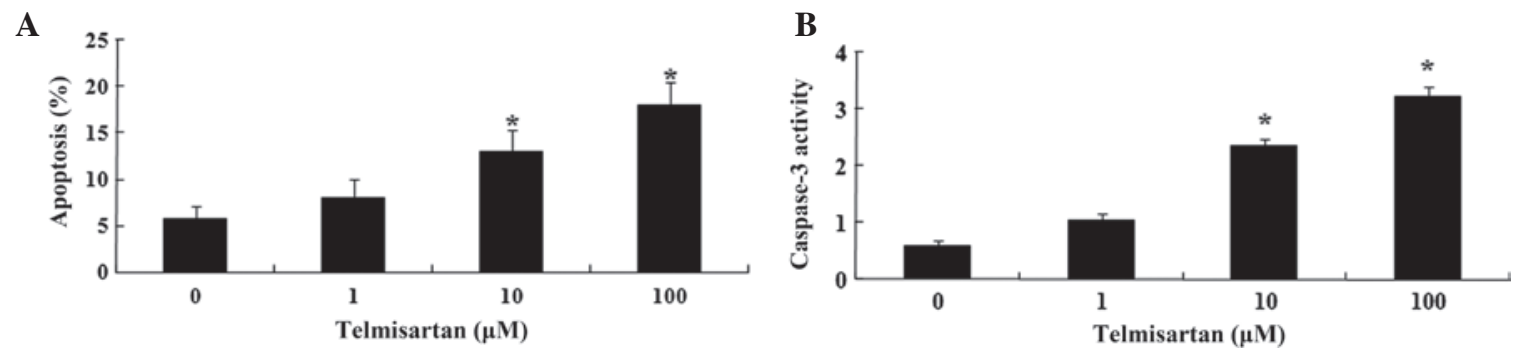

Figure 3. Flow cytometric analysis for detecting cellular apoptosis. (A) Telmisartan treatment dose-dependently promotes apoptosis as determined using flow cytometry. (B) The activity of caspase- 3 in HEY cells. ${ }^{*} \mathrm{P}<0.01$ compared with the $0 \mu \mathrm{M}$ telmisartan treatment group.
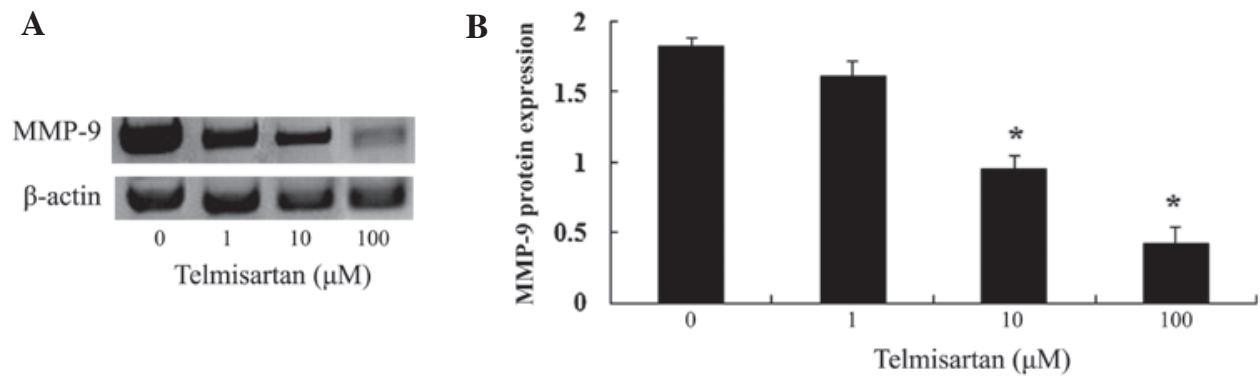

Figure 4. Effect of telmisartan on MMP-9 expression. (A) MMP-9 activity was dose-dependently reduced in HEY cells following treatment with telmisartan for $48 \mathrm{~h}$ as analyzed using gelatin zymography assays. (B) Quantitation of the results of the gelatin zymography assays. "P<0.01 compared with the $0 \mu \mathrm{M}$ telmisartan treatment group. MMP, matrix metalloproteinase.

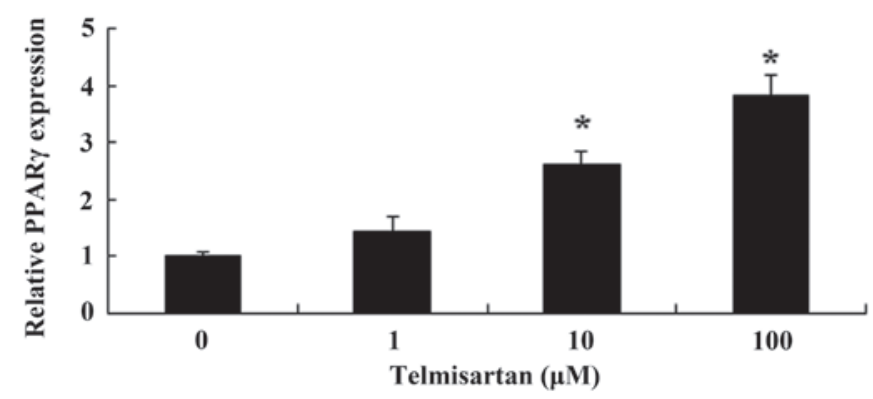

Figure 5. PPAR $\gamma$ expression following treatment with different concentrations of telmisartan $(0,1,10$ and $100 \mu \mathrm{M})$ for $48 \mathrm{~h} .{ }^{*} \mathrm{P}<0.01$ compared with the $0 \mu \mathrm{M}$ telmisartan treatment group.

CAAAdTdT-3' and reverse primer: 5'-dTdTUCCUUUCU GUUGUCUGUUU-3'; and S3 forward primer: 5'-GUACCA AAGUGCAAUCAAAdTdT-3' and reverse primer: 5'-dTdTCA UGGUUUCACGUUAGUUU-3'. PPAR $\gamma$ siRNA $(100 \mathrm{mmol} / \mathrm{l})$ was transfected into HEY cells using Lipofectamine 2000 (Invitrogen; Thermo Fisher Scientific.

Statistical analysis. Data were analyzed using SPSS 13.0 (Chicago, IL, USA). Values are expressed as the mean \pm standard deviation of independent experiments. Differences were analyzed using analysis of variance or Student's paired t-test. $\mathrm{P}<0.05$ was considered to indicate a statistically significant difference.

\section{Results}

MTT analysis of cell proliferation. To evaluate the effect of telmisartan on HEY cells, cell proliferation was measured using an MTT assay. The cells were treated with telmisartan $(0,1,10$ and $100 \mu \mathrm{M})$ for $0,24,48$ and $72 \mathrm{~h}$, which resulted in significantly inhibited growth of HEY cells in a time- and dose-dependent manner (Fig. 2).

Flow cytometric analysis for detecting cellular apoptosis. As telmisartan significantly inhibited the growth of HEY cells, it was further explored whether telmisartan may have an effect on apoptosis. Flow cytometric analysis showed that telmis$\operatorname{artan}$ treatment for $48 \mathrm{~h}$ resulted in concentration-dependent apoptosis of HEY cells (Fig. 3A). Following treatment with telmisartan $(10$ and $100 \mu \mathrm{M})$ for $48 \mathrm{~h}$, the level of apoptosis was significantly increased. In addition, the activity of caspase-3 in HEY cells was significantly increased (Fig. 3B).

Effect of telmisartan on MMP-9 expression. Following treatment $(48 \mathrm{~h})$ with telmisartan $(0,1,10$ and $100 \mu \mathrm{M})$, the expression of MMP-9 protein in HEY cells was analyzed using gelatin zymography assays (Fig. 4A). Treatment with telmisartan at concentrations of 10 and $100 \mu \mathrm{M}$ significantly decreased the expression of MMP-9 protein (Fig. 4B).

Telmisartan activates PPAR $\gamma$ expression. Quantitative analysis of PPAR $\gamma$ expression in HEY cells showed that treatment with telmisartan $(10$ and $100 \mu \mathrm{M})$ for $48 \mathrm{~h}$ could significantly increase the expression of PPAR $\gamma$ (Fig. 5).

PPAR $\gamma$ siRNA can reverse the effects of telmisartan. PPAR $\gamma$ siRNA was transfected into HEY cells. The results indicated that transfection of PPAR $\gamma$ siRNA significantly reduced the expression of PPAR $\gamma$ in HEY cells (Fig. 6A). Notably, it was observed that downregulating the expression of PPAR $\gamma$ could prevent the effects of telmisartan on cell proliferation (Fig. 6B) 
A
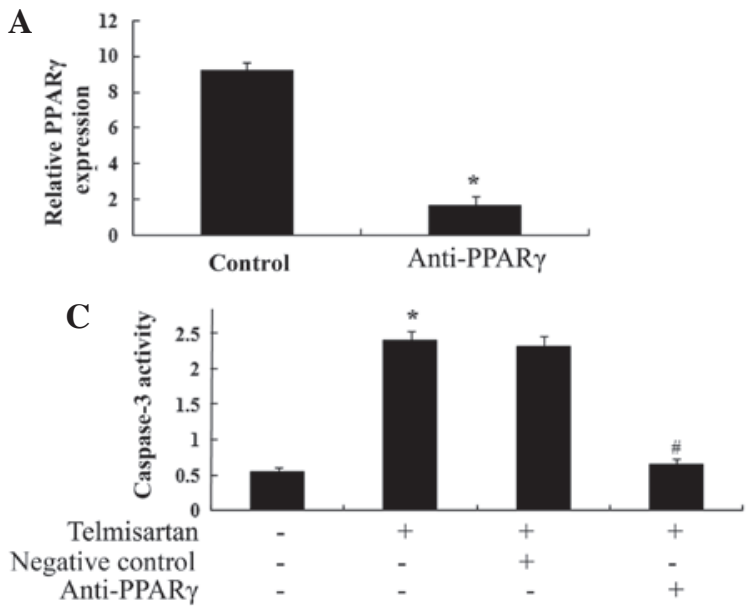

B

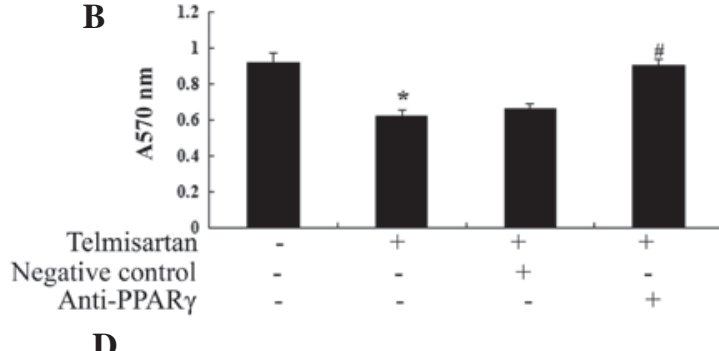

D

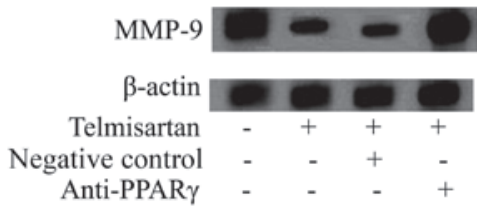

Figure 6. PPAR $\gamma$ siRNA can reverse the effect of telmisartan. (A) PPAR $\gamma$ siRNA decreased the expression of PPAR $\gamma$ in HEY cells. Following treatment with telmisartan $(10 \mu \mathrm{M})$ for $48 \mathrm{~h}$, PPAR $\gamma$ siRNA significantly (B) promoted cell proliferation, (C) inhibited cell apoptosis of HEY cells; and (D) increased MMP-9 expression in HEY cells. ${ }^{*} \mathrm{P}<0.01$ compared with the $0 \mu \mathrm{M}$ telmisartan treatment group and ${ }^{\#} \mathrm{P}<0.01$ compared with the telmisartan-treated group transfected with negative control.

and the activity of caspase-3 (Fig. 6C). It also increased the expression of MMP-9 protein in HEY cells (Fig. 6D) at $48 \mathrm{~h}$.

\section{Discussion}

At present, the mortality rate of ovarian cancer is the highest of all gynecological malignant tumors. Its treatment utilizes the combination of surgery and chemotherapy (21). In the chemotherapy of ovarian cancer, platinum drugs, such as cisplatinum, are important, while the emergence of drug resistance to cisplatinum in ovarian cancer restricts the clinical efficacy (22). Thus, enhancing the sensitivity to chemotherapeutic drugs is key in the treatment of ovarian cancer and is a focus of research. Overall, in the present study it was demonstrated that treatment with telmisartan significantly inhibited the growth of HEY cells in a time- and dose-dependent manner. In addition, telmisartan could also induce apoptosis of HEY cells and decrease the activity of caspase- 3 in HEY cells. In a previous study, it was determined that telmisartan increased the apoptosis of human renal cell carcinoma cells via downregulation of Bcl-2 and involvement of caspase-3 (23). In addition, telmisartan has been previously demonstrated to significantly inhibit growth of human endometrial cancer cells (24).

Through the adjustment of the expression of the relevant genes, PPAR $\gamma$ is important in regulating fat formation, lipid metabolism, energy metabolism and the immune system. In addition, it is associated with the generation and development of numerous diseases, such as diabetes, obesity, metabolic syndrome and hypertension (25). PPAR $\gamma$ is predominantly expressed on the surface of granule cells of follicles during the growth period in ovarian tissue, however, there is only low expression in theca and luteal cells (26). PPAR $\gamma$ participates in the regulation of normal physiology of the ovary, luteinizing hormone peak reduction and the secretion of estrogen and progesterone, which can affect the growth of follicles, ovulation and the quality of ovum (21). In the present study, treatment with telmisartan could significantly increase the expression of PPAR $\gamma$. In addition, a previous study has shown that telmisartan activates PPAR $\gamma$ and does not affect osteoblast differentiation or bone mass (27). Telmisartan can also protect the nutrient deprivation-induced apoptosis of cerebellar granule cells in vitro through activation of the PPAR $\gamma$ pathway (28).

Studies have also demonstrated that in the renal cortex or fiber cells, PPAR $\gamma$ agonists can improve renal tubulointerstitial fibrosis process by preventing cell growth and adjusting the levels of MMP-9, TIMP-1 and TIMP-2 (29,30). In early pregnancy chorionic villi, the expression of PPAR $\gamma$ is negatively correlated with the levels of MMP-2 and MMP-9, which suggests that PPAR $\gamma$ regulates the expression of MMP-2 and MMP-9, affecting the invasion of trophoblast cells (31). The results of the present study showed that treatment with telmisartan could significantly decrease the expression of MMP-9 protein. Araújo et al (32) reported that telmisartan can reduce COX-2, MMP-2, MMP-9 and RANKL/RANK in ligature-induced periodontitis in rats. Telmisartan can weaken acute myocardial infarction through downregulation of MMP-2 and MMP-9 (33). These results suggest that downregulating the expression of PPAR $\gamma$ could restrain the effect of telmisartan on anti-proliferative and apoptotic effects, and up-regulation the expression of MMP-9 protein level in HEY cells. Telmisartan is a novel and specific Ang II receptor antagonist with long term efficiency, which not only effectively decreases blood pressure, but also has anti-inflammatory, anti-thrombotic and other non-antihypertensive effects $(30,34)$. Telmisartan has antihypertensive effects and can affect the expression of PPAR $\gamma$ in muscle. Overall, in addition to inhibiting cell growth by reducing proliferation and inducing apoptosis, telmisartan may have therapeutic potential in ovarian cancer by upregulating PPAR $\gamma$ and downregulating the MMP-9 expression signaling pathway. Further studies are required to clarify additional mechanisms underlying the effects of telmisartan on ovarian cancer cells.

\section{References}

1. Kamangar F, Dores GM and Anderson WF: Patterns of cancer incidence, mortality and prevalence across five continents: Defining priorities to reduce cancer disparities in different geographic regions of the world. J Clin Oncol 24: 2137-2150, 2006. 
2. Des Jarlais G, Kaplan CP, Haas JS, Gregorich SE, Pérez-Stable EJ and Kerlikowske K: Factors affecting participation in a breast cancer risk reduction telephone survey among women from four racial/ethnic groups. Prev Med 41: 720-727, 2005.

3. SalehiF, Dunfield L, Phillips KP, Krewski D and Vanderhyden BC: Risk factors for ovarian cancer: An overview with emphasis on hormonal factors. J Toxicol Environ Health B Crit Rev 11: 301-321, 2008.

4. Vo C and Carney ME: Ovarian cancer hormonal and environmental risk effect. Obstet Gynecol Clin North Am 34: 687-700, viii, 2007.

5. Xie Y,Zhu J, Zhou XJ, Chen J, Lu NH and Wang CW: Expression of peroxisome proliferators-activated receptor-gamma and cyclooxygenase-2 in Helicobacter pylori infection-associated diseases and significance thereof. Zhonghua Yi Xue Za Zhi 86: 2683-2689, 2006 (In Chinese).

6. DuBois RN, Gupta R, Brockman J, Reddy BS, Krakow SL and Lazar MA: The nuclear eicosanoid receptor, PPARgamma, is aberrantly expressed in colonic cancers. Carcinogenesis 19: 49-53, 1998.

7. Jiang WG, Redfern A, Bryce RP and Mansel RE: Peroxisome proliferator activated receptor-gamma (PPAR-gamma) mediates the action of gamma linolenic acid in breast cancer cells. Prostaglandins Leukot Essent Fatty Acids 62: 119-127, 2000.

8. Wijnhoven BP, Lindstedt EW, Abbou M, Ijzendoorn Y, de Krijger RR, Tilanus HW and Dinjens WN; Rotterdam Esophageal Tumor Study Group: Molecular genetic analysis of the von Hippel-Lindau and human peroxisome proliferator-activated receptor gamma tumor-suppressor genes in adenocarcinomas of the gastroesophageal junction. Int J Cancer 94: 891-895, 2001.

9. Chang TH and Szabo E: Induction of differentiation and apoptosis by ligands of peroxisome proliferator-activated receptor gamma in non-small cell lung cancer. Cancer Res 60: 1129-1138, 2000

10. Papi A, De Carolis S, Bertoni S, Storci G, Sceberras V, Santini D, Ceccarelli C, Taffurelli M, Orlandi M and Bonafé M: PPAR $\gamma$ and RXR ligands disrupt the inflammatory cross-talk in the hypoxic breast cancer stem cells niche. J Cell Physiol 229: 1595-1606, 2014

11. Chatterjee A, Kusunoki H, Taniyama Y, Rakugi $H$ and Morishita R: Improvement of metabolic syndrome by irbesartan via the PPAR $\gamma / \mathrm{HGF}$ pathway in apolipoprotein $\mathrm{E}$ knockout mice. Biomed Rep 1: 65-70, 2013

12. Łukaszewicz-Zajac M, Mroczko B, Guzińska-Ustymowicz K, Pryczynicz A, Gryko M, Kemona A, Kędra B and Szmitkowski M: Matrix metalloproteinase 2 (MMP-2) and their tissue inhibitor 2 (TIMP-2) in gastric cancer patients. Adv Med Sci 58: 235-243, 2013.

13. Waite LL, Louie RE and Taylor RN: Circulating activators of peroxisome proliferator-activated receptors are reduced in preeclamptic pregnancy. J Clin Endocrinol Metab 90: 620-626, 2005.

14. Liu J, Lu H, Huang R, Lin D, Wu X, Lin Q, Wu X, Zheng J, Pan X, Peng J, et al: Peroxisome proliferator activated receptor-gamma ligands induced cell growth inhibition and its influence on matrix metalloproteinase activity in human myeloid leukemia cells. Cancer Chemother Pharmacol 56: 400-408, 2005.

15. Balakumar P, Bishnoi HK and Mahadevan N: Telmisartan in the management of diabetic nephropathy: A contemporary view. Curr Diabetes Rev 8: 183-190, 2012.

16. Takagi H, Mizuno Y, Yamamoto H, Goto SN and Umemoto T; All-Literature Investigation of Cardiovascular Evidence Group: Effects of telmisartan therapy on interleukin-6 and tumor necrosis factor-alpha levels: A meta-analysis of randomized controlled trials. Hypertens Res 36: 368-373, 2013.

17. Lacourcière $Y$ : Telmisartan or valsartan alone or in combination with hydrochlorothiazide: A review. Clin Exp Hypertens 35: $50-60,2013$

18. Maejima Y, Okada H, Haraguchi G, Onai Y, Kosuge H, Suzuki J and Isobe M: Telmisartan, a unique ARB, improves left ventricular remodeling of infarcted heart by activating PPAR gamma. Lab Invest 91: 932-944, 2011.
19. Li J, Chen L, Yu P, Liu B, Zhu J and Yang Y: Telmisartan exerts anti-tumor effects by activating peroxisome proliferator-activated receptor- $\gamma$ in human lung adenocarcinoma A549 cells. Molecules 19: 2862-2876, 2014.

20. Shi M, Cao M, Song J, Liu Q, Li H, Meng F, Pan Z, Bai J and Zheng J: PinX1 inhibits the invasion and metastasis of human breast cancer via suppressing NF- $\mathrm{KB} / \mathrm{MMP}-9$ signaling pathway. Mol Cancer 14: 66, 2015.

21. Mozzetti S, Ferlini C, Concolino P, Filippetti F, Raspaglio G, Prislei S, Gallo D, Martinelli E, Ranelletti FO, Ferrandina G and Scambia G: Class III beta-tubulin overexpression is a prominent mechanism of paclitaxel resistance in ovarian cancer patients. Clin Cancer Res 11: 298-305, 2005.

22. Kamat AA, Kim TJ, Landen CN Jr, Lu C, Han LY, Lin YG, Merritt WM, Thaker PH, Gershenson DM, Bischoff FZ, et al: Metronomic chemotherapy enhances the efficacy of antivascular therapy in ovarian cancer. Cancer Res 67: 281-288, 2007.

23. de Araújo Júnior RF, Leitão Oliveira AL, de Melo Silveira RF, de Oliveira Rocha HA, de França Cavalcanti P and de Araújo AA Telmisartan induces apoptosis and regulates Bcl-2 in human renal cancer cells. Exp Biol Med (Maywood) 240: 34-44, 2015.

24. Koyama N, Nishida Y, Ishii T, Yoshida T, Furukawa $Y$ and Narahara H: Telmisartan induces growth inhibition, DNA double-strand breaks and apoptosis in human endometrial cancer cells. PLoS One 9: e93050, 2014

25. Auwerx J: PPARgamma, the ultimate thrifty gene. Diabetologia 42: 1033-1049, 1999.

26. Komar CM: Peroxisome proliferator-activated receptors (PPARs) and ovarian function-implications for regulating steroidogenesis, differentiation and tissue remodeling. Reprod Biol Endocrinol 3: 41, 2005.

27. Kolli V, Stechschulte LA, Dowling AR, Rahman S, Czernik PJ and Lecka-Czernik B: Partial agonist, telmisartan, maintains PPAR $\gamma$ serine 112 phosphorylation, and does not affect osteoblast differentiation and bone mass. PLoS One 9: e96323, 2014.

28. Pang T, Sun LX, Wang T, Jiang ZZ, Liao H and Zhang LY: Telmisartan protects central neurons against nutrient deprivation-induced apoptosis in vitro through activation of PPAR and the Akt/GSK-3 $\beta$ pathway. Acta Pharmacol Sin 35: 727-737, 2014.

29. Yiqin Y, Meilin X, Jie X and Keping Z: Aspirin inhibits MMP-2 and MMP-9 expression and activity through PPARalpha/gamma and TIMP-1-mediated mechanisms in cultured mouse celiac macrophages. Inflammation 32: 233-241, 2009.

30. Funao K, Matsuyama M, Kawahito Y, Sano H, Chargui J, Touraine JL, Nakatani T and Yoshimura R: Telmisartan as a peroxisome proliferator-activated receptor- $\gamma$ ligand is a new target in the treatment of human renal cell carcinoma. Mol Med Rep 2: 193-198, 2009.

31. Zafiriou S, Stanners SR, Saad S, Polhill TS, Poronnik P and Pollock CA: Pioglitazone inhibits cell growth and reduces matrix production in human kidney fibroblasts. J Am Soc Nephrol 16: 638-645, 2005

32. Araújo AA, Souza TO, Moura LM, Brito GA, Aragão KS, Araújo LS, Medeiros CA, Alves MS and Araújo RF Jr: Effect of telmisartan on levels of IL-1, TNF- $\alpha$, down-regulated COX-2, MMP-2, MMP-9 and RANKL/RANK in an experimental periodontitis model. J Clin Periodontol 40: 1104-1111, 2013.

33. Yokota T, Osanai T, Hanada K, Kushibiki M, Abe N, Oikawa K, Tomita H, Higuma T, Yokoyama J, Hanada H and Okumura K: Effects of telmisartan on markers of ventricular remodeling in patients with acute myocardial infarction: Comparison with enalapril. Heart Vessels 25: 460-468, 2010.

34. Wu J, Lin H, Liu D, Liu J, Wang N, Mei X, Sun J, Yang G and Zhang X: The protective effect of telmisartan in Type 2 diabetes rat kidneys is related to the downregulation of thioredoxin-interacting protein. J Endocrinol Invest 36: 453-459, 2013. 